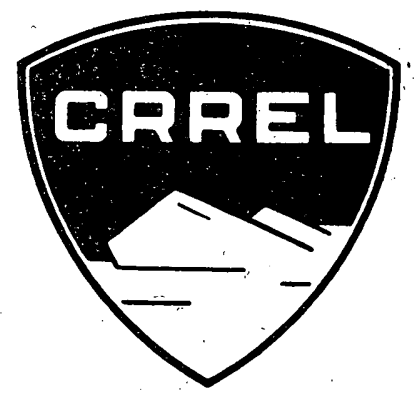

Research Report 183

\title{
MIGRATION OF LIQUID INCLUSIONS IN SINGLE ICE CRYSTALS
}

by

P. Hoekstra, T. E. Osterkamp and W. F. Weeks

DECEMBER 1965

\section{U.S. ARMY MATERIEL COMMAND}

COLD REGIONS RESEARCH \& ENGINEERING LABORATORY HANOVER, NEW HAMPSHIRE

DA Task IV014501B $52 A 02$

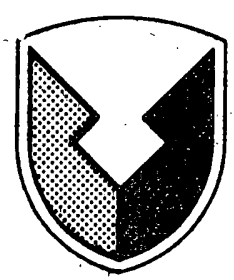


PREFACE

This paper was prepared by Dr. P. Hoekstra and T. E. Osterkamp, Physicists, and Dr. W. F. Weeks, Geologist. It constitutes an interim report accomplished in conjunction with U. S. Army Cold Regions ${ }^{*}$ Research and Engineering Laboratory (USA CRREL) research project Properties and Phase Relations of Salt Ice (Materials Research Branch).

USA CRREL is an Army Materiel Command laboratory.

Manuscript received 14 June 1965

DA Task IVO14501 B52A02 


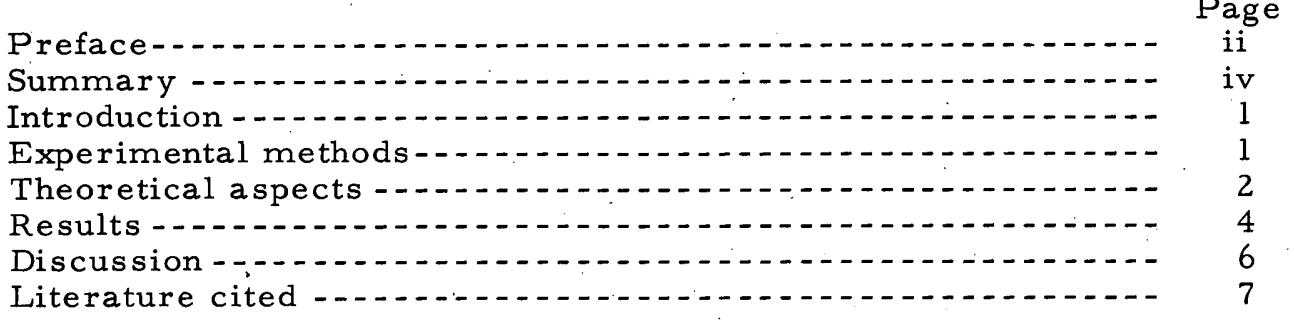

\section{ILLUSTRATIONS}

Figure

1. Liquid inclusions of $\mathrm{NaCl}$ brine in single crystal ice -..-

2. Relation between velocity of brine pocket migration caused by a temperature gradient of $1 \mathrm{C} / \mathrm{cm}$ and temperature -...........................

3. Velocity of brine pocket migration in the temperature range $-8.6 \mathrm{C}$ to $-8.9 \mathrm{C}$ as affected by the temperature gradient - .

\section{TABLES}

Table

I. Theoretical values for concentration, c; diffusion coefficient, D; slope of the liquidus curve, dc/dt; and the migration velocity, $\mathrm{v}$; of $\mathrm{NaCl}$ and $\mathrm{KCl}$ brine pockets as a function of temperature -............

II. Effect of crystal orientation on $\mathrm{NaCl}$ and $\mathrm{KCl}$ brine pockets under a temperature gradient of $1 \mathrm{C} / \mathrm{cm}$,

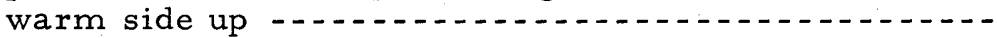

III. Effect of gravity on $\mathrm{KCl}$ brine pocket migration rate under a $1 \mathrm{C} / \mathrm{cm}$ temperature gradient, c-axis in the horizontal plane 


\section{SUMMARY}

The migration of brine pockets of $\mathrm{KCl}$ and $\mathrm{NaCl}$ under the influence of a temperature gradient was investigated in single ice crystals. The observed migration velocities are compared with velocities calculated from a simple diffusion model using the data on electrolytic solutions available in the literature. Although the relative movements of $\mathrm{KCl}$ and $\mathrm{NaCl}$ pockets were consistent with the diffusion theory, the observed velocities were always less than the calculated. Neither the direction of the gravitational field nor the crystallographic orientation of the host crystal significantly influenced the rate of migration. It was also showri that the migration of solid $\mathrm{KCl}$ particles occurs at temperatures below the eutectic point. Two mechanisms are proposed that would impede the mechanical differentiation of salts that crystallize at high temperatures relative to salts that remain in the brine of sea ice. These mechanisms explain recent field observations that the $\mathrm{SO}_{4} / \mathrm{Cl}$ ratio of sea ice does not increase with the age of the ice. 


\title{
MIGRATION OF LIQUID INCLUSIONS IN SINGLE ICE CR YSTALS
}

\author{
by
}

\author{
P. Hoekstra, T. E. Osterkamp and W. F. Weeks
}

\section{INTRODUCTION}

Since the early experiments of Whitman (1926) on the elimination of salt from sea ice, only a few papers have appeared studying the basic mechanisms of this process. Whitman (1926) observed that under the influence of a temperature gradient brine migrated toward the warmer end of the ice sample regardless of the direction of the gravitational field. Therefore he suggested that brine pocket diffusion was the dominant mechanism. In the metallurgical literature, where it is the subject of considerable interest (Pfann, 1958; Tiller, 1963), this process is now commonly referred to as temperature-gradient zone melting. Further work on sea ice by Goodnow and Kingery (1963) suggests that although brine pocket diffusion does occur in natural sea ice, it is much less important than bulk brine drainage through interconnected brine channels under the influence of gravity. Since both brine pocket diffusion and gravity drainage occur simultaneously, it is difficult to separate the two processes in sea ice. In addition, because of the large number of brine pockets occurring in either natural or artificial sea ice, it is easy to lose a brine pocket during migration as a result of its merging with other pockets, disappearing along grain boundaries, or simply getting lost in the crowd. Therefore, in our investigation brine pocket diffusion was isolated by measuring the movement of individual brine inclusions artificially introduced into single crystals of glacier ice. The effect of the orientation of the host crystal and the direction of the gravitational field on the migration velocity was also investigated.

It was hoped that these experiments would offer an opportunity for evaluating how adequately the movement of a brine pocket in ice can be described by a simple diffusion theory or whether it is necessary to use more complex relations such as those developed by Tiller. In addition it was felt that these experiments might provide further insight into the mechanisms effecting the removal of liquid brine and solid salt particles from natural sea ice.

\section{EXPERIMENTAL METHODS}

The ice specimens used were from large single crystals obtained from Mendenhall Glacier, Alaska. The orientation of each crystal was determined with a universal stage. The samples were prepared in a cold shop at $-10 \mathrm{C}$ where the crystals were cut to the desired size and holes were drilled to accommodate the thermistors and reference points which were frozen into place using distilled water. Brine pockets were introduced into the single crystal by placing, with a syringe, a few drops of a concentrated salt solution in the bottom of a fine drill hole. The specimen temperature was then lowered to freeze the brine and the rest of the hole was sealed with distilled water.

The single crystal was placed between two horizontal brass cooling plates through which a coolant (methanol-water) from a constant temperature $( \pm 0.1 \mathrm{C})$ bath was circulated. The sides of the crystal were insulated with styrofoam and the ambient temperature of the room in which the experiments were performed was $-5 \mathrm{C}$. A.djustment of the constant temperature baths allowed the application of any desired temperature gradient in the ice sample. The initial brine pockets, after moving for a few days under the influence of a temperature gradient, invariably broke up into small pockets ( $<35 \mu$ in radius). All brine pocket migration measurements were taken after this break-up had occurred.

Photographs were taken with a Bausch and Lomb model 4 camera and a magnification of up to $30 X$ could be achieved with the available lens system. To obtain a 
good contrast between the brine and the surrounding ice, shadow photography was used. An example of a typical photograph is shown in Figure 1. Polaroid Land film type $55 / \mathrm{p} / \mathrm{n}$ was used, which gives both a positive and a negative. The negatives were mounted between glass plates and projected on a screen. The positions of a given brine pocket vs time were then measured and the velocities calculated.

\section{THEORETICAL ASPECTS}

The migration of brine pockets through ice offers a unique opportunity for evaluating the present theories on the migration of liquid zones through solids under temperature gradients, because the factors influencing the movement of the pocketsuch as the diffusion constant, $D=D(c, t)$; the Soret coefficient; $s=s(c, t)$; and the slope of the liquidus curve, $\mathrm{dc} / \mathrm{dt}=\mathrm{k}(\mathrm{t})$-are known to a considerable degree of accuracy for simple salt solutions. Here $\mathrm{c}$ represents the concentration of solute (salt) in the brine pocket and the temperature. At temperatures where ice and brine coexist, the se simple two-component salt-water systems are univariate, i.e., $t$ uniquely determines $c$ and vice versa. Therefore for the remainder of this paper we can consider $D=D(t)$ and $s=s(t)$. Also the solid $\rightleftharpoons$ liquid phase transition (ice $\rightleftharpoons$ water) occurs at a convenient temperature and the solid solvent (ice) is transparent.

The driving force for the migration of liquid zones through solids under the influence of a temperature gradient has been considered to be the difference in composition between the warm and the cold side of the zone. The concentration gradient of a solute in this zone is determined by the temperature gradient across the zone $\mathrm{dt} / \mathrm{dx}$ and the slope of the liquidus curve $\mathrm{dc} / \mathrm{dt}$ as specified by the phase diagram. This treatment has been used to analyze the gross aspects of both the movement of molten zones in metals (Pfann, 1958; Wernick, 1956) and the brine pocket migration in ice (Goodnow and Kingery, 1963).

The steady-state migration of a brine pocket can be described in this theory by a simple diffusion equation, if it is assumed that the shape of the brine pocket remains the same. The flux of solute in the brine pocket $\mathrm{J}$ can be expressed in terms of the migration velocity of the brine pocket $v$ and the brine concentration $c$ as

$$
\mathrm{c} v=\mathrm{J} \text {. }
$$

In applying theories developed to treat the movement of molten zones in metals to brine pocket migration in ice, one important simplification can be made. Because for salt-water systems the solute partition coefficient ( $k=$ concentration salt in solid/ concentration salt in liquid) is very small (i.e., $\mathrm{k}<10^{-4}$ ), effectively all salts are excluded from the ice phase. Therefore the flux of solute at a freezing face $\mathrm{c} v(1-\mathrm{k}) \sim \mathrm{c} v$. For the steady state, eq 1 can be written in terms of the concentration gradient $\mathrm{dc} / \mathrm{dx}$ as:

$$
\mathrm{c} v=-\mathrm{D} \frac{\mathrm{dc}}{\mathrm{dx}} \text {. }
$$

Then substituting

$$
\frac{d c}{d x}=\frac{d c}{d t} \cdot \frac{d t}{d x}
$$

where dc/dt is specified by the phase diagram, the migration velocity of the brine pocket is given by

$$
\mathrm{v}=-\frac{\mathrm{D}}{\mathrm{c}} \frac{\mathrm{dc}}{\mathrm{dt}} \cdot \frac{\mathrm{dt}}{\mathrm{dx}} .
$$

However, since $D=D(t), c=c(t)$ and $d c / d t=k(t)$, eq 4 should be written in the form

$$
v(t)=-\frac{D(t)}{c(t)}\left(\frac{d c}{d t}\right)_{t} \frac{d t}{d x} .
$$

*See Note, p. 8 


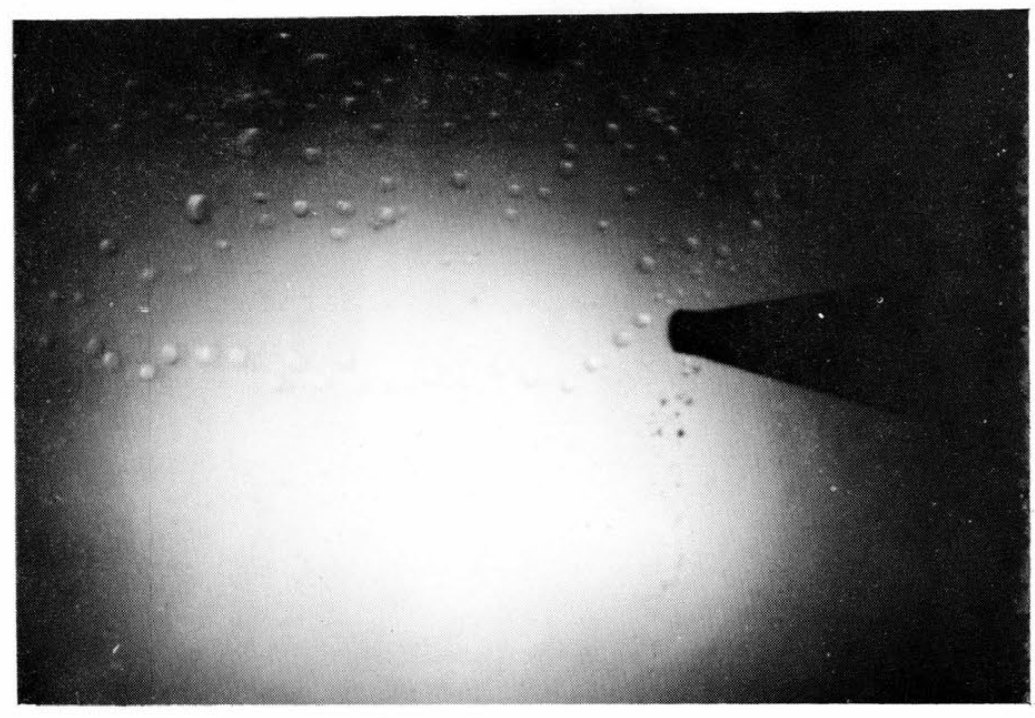

Figure 1. Liquid inclusions of $\mathrm{NaCl}$ brine in single crystal ice.

In this model, as long as the shape of the brine pocket does not change, the velocity of migration is independent of the size of the pocket and the direction of movement with respect to crystal orientation.

The work of Wernick (1957) showed that in certain alloy systems the rate of migration of a liquid zone also depends upon the size of the zone and the crystallographic orientation of the host crystal relative to the direction of the temperature gradient. Tiller (1963) developed further relations taking into account the kinetics of melting and freezing. To arrive at an expression for $\mathrm{v}$, he combined equations relating $\mathrm{v}$ to the mechanism of growth, the temperature gradient, and the mass transport in the liquid zone. Tiller, however, did not consider how $\mathrm{v}$ is affected by the fact that $D=D(t)$ and $d c / d t=k(t)$. Moreover, several constants in his final equation are difficult to evaluate experimentally at the present. Because the brine pockets measured in the present study were all roughly the same size, no attempt was made to study the relation between $v$ and the size of the pocket.

Wernick (1956) considered the flux of the diffusing solute caused solely by a temperature gradient and concluded that, for metal systems, thermal diffusion is small compared to diffusion caused by the concentration gradient set up in a molten zone. For binary electrolytic solutions, such as $\mathrm{KCl}$ and $\mathrm{NaCl}$, the effect of thermal diffusion can be calculated from existing data. To take thermal diffusion into account in a system where a one-dimensional temperature gradient is imposed, the expression for the solute flux J (eq 2) must be rewritten as

$$
J=-D\left\lceil\frac{d c}{d x}+c s \frac{d t}{d x}\right\rceil
$$

where $\mathrm{s}$ is the Soret coefficient, which is concentration-and temperature-dependent. Fitts (1962, p. 111) gives $\mathrm{s}$ as a function of temperature and concentration for $\mathrm{NaCl}$ and $\mathrm{KCl}$ solutions. The value of $\mathrm{s}$ for $\mathrm{KCl}$ solutions decreases rapidly with temperature and extrapolates to $+0.4 \times 10^{-3} \mathrm{C}^{-1}$ at $-5 \mathrm{C}$. A positive value indicates that $\mathrm{KCl}$ migrates from the cold toward the warm side of the brine pocket. If the temperature gradient in the ice is $1 \mathrm{C} / \mathrm{cm}$, thermal diffusion would set up a concentration gradient of $8 \times 10^{-4}$ moles/liter - $\mathrm{cm}$ in the brine pocket. On the other hand the concentration gradient calculated from the phase diagram of $\mathrm{KCl}$ for a temperature gradient of $1 \mathrm{C} / \mathrm{cm}$ is .32 moles/liter $-\mathrm{cm}$. This indicates that for $\mathrm{KCl}$ the effect 
of thermal diffusion is at least $10^{-2}$ times smaller than the diffusion caused by the differences in concentration between the warm and cold sides of the brine pocket. Calculated values for $\mathrm{NaCl}$ solutions are of the same magnitude. Therefore, for the purpose of this paper, thermal diffusion will be neglected.

The velocity of migration predicted by eq 5 can be calculated using the slope of the liquidus curve dc/dt from the phase diagram and Harned and Owen's (1958, p. 255) listing of the diffusion constant at $25 \mathrm{C}$ as a function of concentration. In the diffusion equation the activity gradient rather than the concentration gradient is the driving force for diffusion. Because the $\mathrm{D}$ values listed by Harned and Owen are corrected by the activity coefficients eq 5 can be used directly.

The temperature correction on the diffusion constant was made according to the theoretical expression for the diffusion constant (Harned and Owen, 1958, p. 243); this expression shows D directly proportional to t degrees Kelvin, so that $D(-5 C)=(268 / 298) \cdot D(+25 C)=0.9 D(+25 C)$. In Table I, values of $c, D, d c / d t$, and the velocity of brine pocket migration $\mathrm{v}$ (calculated using eq 5) are given for $\mathrm{NaCl}$ and

- KCl. These data are plotted in Figure 2 together with the experimental values.

Table I. Theoretical values for concentration c, diffusion coefficient $D$, slope of the liquidus curve dc/dt, and the migration velocity $\mathrm{v}$ of $\mathrm{NaCl}$ and $\mathrm{KCl}$ brine pockets as a function of temperature.

\begin{tabular}{|c|c|c|c|c|}
\hline \multicolumn{5}{|c|}{$\mathrm{NaCl}$} \\
\hline Temp (C) & $\begin{array}{c}\mathrm{c} \\
\text { (moles/liter) } \\
\end{array}$ & $\begin{array}{c}\mathrm{D} \times 10^{5} \\
\left(\mathrm{~cm}^{2} / \mathrm{sec}\right) \\
\end{array}$ & $\begin{array}{c}\mathrm{dc} / \mathrm{dt} \\
\text { (moles/liter-C) } \\
\end{array}$ & $\begin{array}{c}\mathrm{v} \\
(\mu / \mathrm{hr} \text { per C } / \mathrm{cm})\end{array}$ \\
\hline $\begin{array}{l}-4 \\
-6 \\
-8 \\
-10 \\
-12 \\
-14 \\
-16\end{array}$ & $\begin{array}{l}1.10 \\
1.59 \\
2.00 \\
2.38 \\
2.74 \\
3.05 \\
3.35\end{array}$ & $\begin{array}{l}1.50 \\
1.50 \\
1.52 \\
1.53 \\
1.55 \\
1.57 \\
1.58\end{array}$ & $\begin{array}{l}.26 \\
.24 \\
.21 \\
.17 \\
.16 \\
.15 \\
.15\end{array}$ & $\begin{array}{r}148 . \\
82 . \\
57 . \\
39 . \\
33 . \\
28 . \\
25 .\end{array}$ \\
\hline \multicolumn{5}{|c|}{$\mathrm{KCl}$} \\
\hline $\begin{array}{l}-4 \\
-\quad 5 \\
-6 \\
-7 \\
-\quad 8 \\
-9 \\
-10\end{array}$ & $\begin{array}{l}1.26 \\
1.58 \\
1.90 \\
2.22 \\
2.51 \\
2.80 \\
3.10\end{array}$ & $\begin{array}{l}1.73 \\
1.76 \\
1.79 \\
1.82 \\
1.85 \\
1.88 \\
1.91\end{array}$ & $\begin{array}{l}.32 \\
.32 \\
.32 \\
.32 \\
.31 \\
.30 \\
.29\end{array}$ & $\begin{array}{r}157 . \\
128 . \\
108 . \\
95 . \\
80 . \\
70 . \\
67 .\end{array}$ \\
\hline
\end{tabular}

\section{RESULTS}

The migration of both $\mathrm{NaCl}$ and $\mathrm{KCl}$ brine pockets was measured. The main objective of the experiment was to verify whether the brine pocket movement in ice can be adequately described by the simple diffusion eq 5 . Only measurements on brine pockets which did not change shape during the time of observation were used. With this restriction on the data, our measurements were in general reproducible to $\pm 2.5 \mu / \mathrm{hr}$.

To establish the dependence of the brine-pocket migration rate on the temperature gradient, migration was measured at several different temperature gradients. Since the velocity is also dependent on the actual temperature at the location of the brine pocket, the influence of the temperature gradient on velocity must be evaluated on brine pockets at approximately the same temperature. In Figure 3 the velocity of migration is plotted against the imposed temperature gradient for brine pockets in 


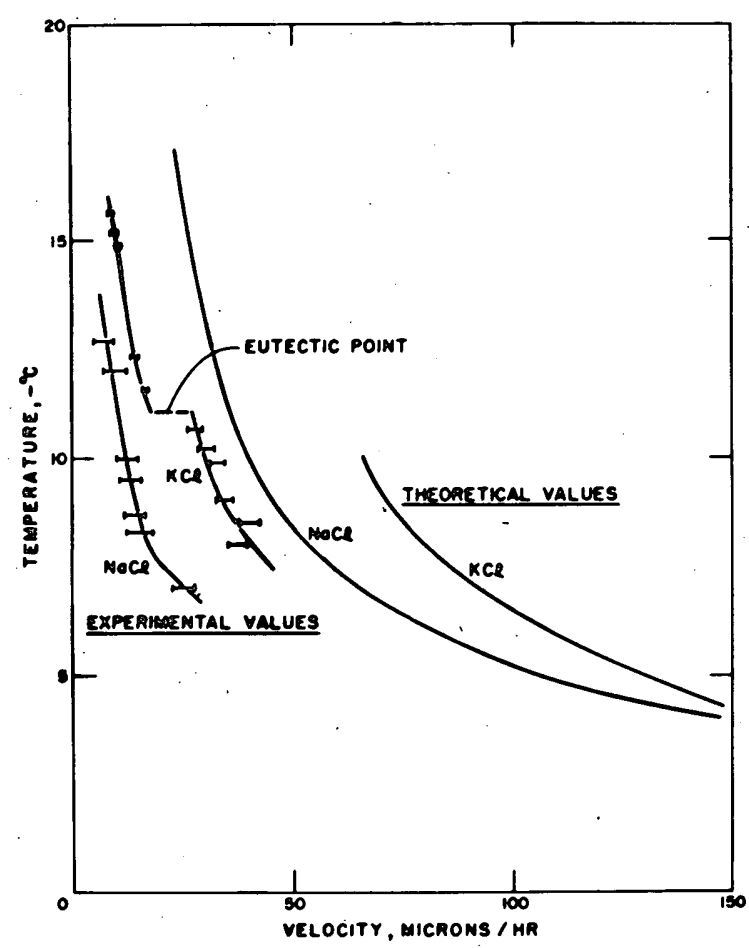

Figure 2. Relation between velocity of brine pocket migration caused by a temperature gradient of $1 \mathrm{C} / \mathrm{cm}$ and temperature.

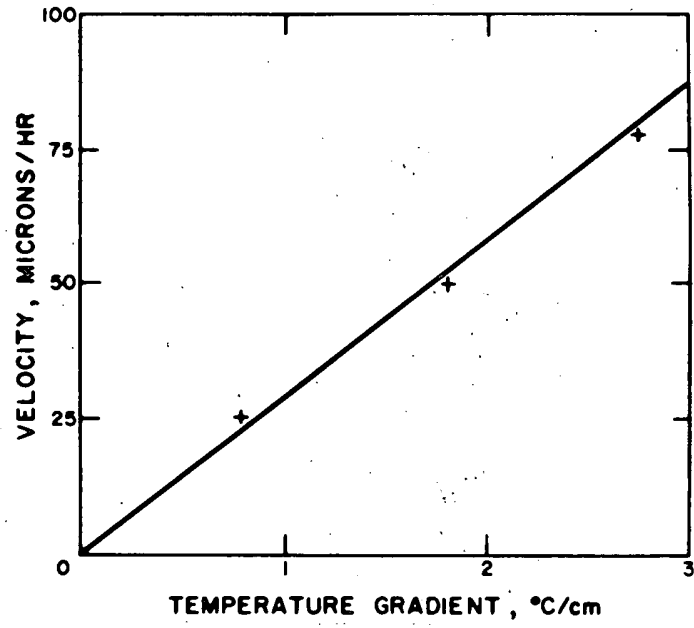

Figure 3. Velocity of brine pocket migration in the temperature range $-8.6 \mathrm{C}$ to $-8.9 \mathrm{C}$ as affected by the temperature gradient.

the temperature range $-8.6 \mathrm{C}$ to $-8.9 \mathrm{C}$. It can be concluded that for brine pockets in the same temperature range the velocity is directly proportional to the temperature gradient. Although this is consistent with'eq 5, other mechanisms proposed (Tiller, 1963) also give a linear relationship between the imposed temperature gradient and the velocity.

The experimental values plotted in Figure 2 are consistently smaller than the theoretical values. However, the observed change of velocity with temperature has the same form as the theoretical values. Also, the respective rates of movement of $\mathrm{KCl}$ and $\mathrm{NaCl}$ pockets are consistent with the diffusion equation. This is an important argument against the significant influence of the kinetics of melting and freezing as the dominant rate-controlling mechanism; one would not expect the kinetics of melting and freezing of ice to change significantly with the kind of salt used. If the kinetics of melting and freezing appreciably influence the rate of brine diffusion, one would also expect a different rate when the migration direction is changed with respect to the crystal orientation. The present data show no strong influence of crystal orientation on the rate of brine pocket migration (Table II) even though the kinetic factors governing ice growth are known to be a strong function of crystal orientation (Hillig, 1958). The temperature correction to - $10 \mathrm{C}$ in Table II was made assuming change in velocity with temperature independent of crystal orientation.

No significant difference in the rate of brine-pocket migration was found when the temperature gradient was in or against the direction of the gravitational field (Table III). Gravity will increase the rate of migration in a downward direction if convection occurs in the brine pockets (Tiller, 1963). The lack of influence of the direction of the gravitational field on the migration velocity is presumably the result of the small size of the brine pockets, which would inhibit convection. These results also suggest that convection never has a significant effect in brine pocket migration in natural sea ice because of the observed tendency for the larger brine pockets to 
Table II. Effect of crystal orientation on $\mathrm{NaCl}$ and $\mathrm{KCl}$ brine pockets under a temperature gradient of $1 \mathrm{C} / \mathrm{cm}$, warm side up.

Temperature at

location of pocket, C Salt

$-9.7$

$-13: 0$

$-9.7$

$-10.2$

$-9.1$

$-8.3$

$-8.6$

$-9.9$

$\mathrm{KCl}$

$\mathrm{KCl}$

$\mathrm{KC1}$

$\mathrm{KC} 1$
Uncorrected migration velocity, $\mu / \mathrm{hr}$

\begin{tabular}{ll}
\hline c-axis & c-axis \\
horizontal & vertical
\end{tabular}

15

13

$\mathrm{NaC}$

$\mathrm{NaCl}$

$\mathrm{NaCl}$ \begin{tabular}{l}
$\begin{array}{l}\text { Migration velocity cor- } \\
\text { rected to }-10 C_{\diamond} \mu / \mathrm{hr}\end{array}$ \\
\hline $\begin{array}{ll}\text { c-axis } & \text { c-axis } \\
\text { horizontal } & \text { vertical }\end{array}$
\end{tabular}

14

10
13

12

24

25

14

12

33

32
26

31

Table III. Effect of gravity on $\mathrm{KCl}$ brine pocket migration rate under a $1 \mathrm{C} / \mathrm{cm}$ temperature gradient, $\mathrm{c}$-axis in the horizontal plane.

Temperature at location of pocket, C

$-7.9$

$-8.2$

$-7.8$

$-7.5$

$-7.2$
Uncor rected migration velocity, $\mu / h \mathbf{r}$

Warm side up Warm side down
Migration velocity corrected to $-8 \mathrm{C}, \mu / \mathrm{hr}$

Warm side up Warm side down
42

39
43

44

46
41

4.1
41

39

38

break into several smaller pockets. In view of these results the fact that Goodnow and Kingery (1963) found no appreciable migration of salt against gravity reinforces their conclusion that brine drainage instead of brine diffusion was the dominant mechanism in their experiments.

Several factors could cause the deviation of the experimental values from the theoretical values. The direction and the magnitude of the errors these factors might introduce could not be evaluated. Two such factors are the following:

a) The concentration of the brine in equilibrium with ice at a certain temperature is evaluated from the liquidus curve. However, the brine pocket is not in a state of thermodynamic equilibrium with ice; e.g., there is a temperature gradient in the system. In effect, the assumption is that the change in partial molal free energy with temperature is the same for ice as for brine.

b) Although the shape of brine pockets measured did not change in the twodimensional plane of focus during the time of observation, the shape in the other dimensions could have changed.

\section{DISCUSSION}

In all previous publications on the physics of sea ice, it has been tacitly assumed that there is no migration of solid-salt particles through the ice. Therefore at a temperature below the eutectic point of the particular salt in question, no migration would be anticipated. For sea ice in the temperature range from -8.2 to -22 . $9 \mathrm{C}$, $\mathrm{Na}_{2} \mathrm{SO}_{4} \cdot 10 \mathrm{H}_{2} \mathrm{O}$ is in crystalline form. It was, therefore, assumed that the solid $\mathrm{Na}_{2} \mathrm{SO}_{4} \cdot 10 \mathrm{H}_{2} 0$ particles remain fixed in the ice while chloride-rich brine drains 
down and out of the ice, increasing the $\mathrm{SO}_{4} / \mathrm{Cl}$ ratio in the ice. Also if the $\mathrm{SO}_{4} / \mathrm{Cl}$ ratio increases, the temperature at which $\mathrm{Na}_{2} \mathrm{SO}_{4} \cdot 10 \mathrm{H}_{2} 0$ will go back into brine increases until it reaches $-1.1 \mathrm{C}$ for a pure $\mathrm{Na}_{2} \mathrm{SO}_{4}-\mathrm{H}_{2} 0$ system. The field evidence for this increase in the $\mathrm{SO}_{4} / \mathrm{Cl}$ ratio has been rather contradictory. For instance Pettersson (1883), Wiese (1930), and Laktionov. (see Zubov, 1963) have noted increases in the $\mathrm{SO}_{4} / \mathrm{Cl}$ ratio. The studies of Malmgren (1927) and Sverdrup (1929), on the other hand, suggest that there is no significant change in the ion ratios. More recently the careful work of Bennington (1963) strongly indicates that the ratios between the more abundant salts are not significantly different in sea ice than in sea water and remain essentially constant during freezing or slow leaching. Only the total amount of salt varies.

To explain these latter field observations, it is necessary to have a mechanism by which the solid salts that crystallize at temperatures only slightly below the freezing point of sea water $\left(\mathrm{CaCl}_{3} \cdot 6 \mathrm{H}_{2} 0,-2.2 \mathrm{C} ; \mathrm{Na}_{2} \mathrm{SO}_{4} \cdot 10 \mathrm{H}_{2} 0,-8.2 \mathrm{C} ; \mathrm{NaCl} \cdot 2 \mathrm{H}_{2} 0\right.$, -22. 9C; Assur, 1958) can continue their downward movement through the ice at velocities approaching the migration rates of the remaining brine pockets. Figure 2 suggests one such mechanism. Note that, although there is a discontinuity in the $\mathrm{KCl}$ salt inclusion velocity vs temperature curve at $-10.9 \mathrm{C}$ (the $\mathrm{KCl}-\mathrm{H}_{2} 0$ eutectic temperature), the solid salt particles continue to move through the ice under the influence of the temperature gradient. This migration of solid salt particles is reasonable in view of recent studies of Hoekstra and Miller (1965) on the migration of glass particles through ice. They showed that movement of solid particles occurs as long as there is a film of "unfrozen water" between the particles and the ice. The migration velocity of solid salt particles through ice sets a lower limit on the rate at which very cold natural sea ice becomes desalinated.

Besides the migration of particles through ice under the influence of a temperature gradient, solid particles have also been found to move in front of a growing ice interface (Corte, 1964; Hoekstra and Miller, 1965). The velocity of growth of an interface required to trap a solid particle increases with decreasing size of the particle. The rate at which particles of $5-20 \mu$ can be moved by an advancing ice interface is larger than the rate of brine pocket migration. In the temperature range of most sea ice $(-2$ to $-20 \mathrm{C})$, the brine pockets contain only a small amount of solid salt, in the form of extremely small crystals, relative to the total amount of brine. Therefore, as the brine inclusions migrate, the advancing ice-brine interface will sweep the solid salt particles ahead of the interface, preventing the salt particles from becoming trapped in the ice. It seems plausible that the ice will not entrap the salt particles until the brine pockets have completely solidified. Because natural sea ice is rarely subjected to such extremely low temperatures, pronounced changes in the ratios of the major salts in sea ice should not be expected.

\section{LITERA TURE CITED}

Assur, A. (1958) "Composition of sea ice and its tensile strength" in Arctic sea ice, National Academy of Sciences, National Research Council, Publication.598, p. 106-138. Also U. S. Army Snow, Ice and Permafrost Research Establishment (USA SIPRE) Research Report 44 (1961).

Bennington, K. O. (1963) "Some chemical composition studies on arctic sea ice" in Ice and snow, properties, processes, and applications (W. D. Kingery, Editor). Cambridge, Mass.: M.I. T. Press, p. 248-257.

Corte, A. E. (1962) Vertical migration of particles in front of a moving freezing plane, Journal of Geophysical Research, vol. 67, p. 1085-1090. Also U. S. Army Cold Regions Research and Engineering Laboratory (USA CRREL) Research Report 105 (1963).

Fitts; D. D. (1962) Nonequilibrium thermodynamics. New York: McGraw-Hill, $173 p$. 


\section{LITERATURE CITED (Cont'd)}

Goodnow, W. H. and Kingery, W. D. (1963) "Brine migration in salt ice" in Ice and snow, properties, processes, and applications (W. D. Kingery, Editor). Cambridge, Mass.: M.I. T. Press, p. 237-247.

Harned, H. S. and Owen, B. B. (1958) The physical chemistry of electrolytic solutions. New York: Reinhold Publishing Corporation, 3rd edition, 803p.

Hillig, W. B. (1958) "The kinetics of freezing of ice in the direction perpendicular to the basal plane" in Growth and perfection of crystals (R. H. Doremus, B. W. Roberts, and D. Turnbull, Editors). New York: Wiley and Sons, p. 350-359.

Hoekstra, P. and Miller, R. D. (1965) The movement of water in a film between glass and ice, USA CRREL Research Report 153.

Malmgren, F. (1927) On the properties of sea ice, Scientific Results, Norwegian North Pole Expedition with the "Maud,"1918-1925, vol. 1, no. 5, 67p.

Pettersson, S. O. (1883) Die Eigenschaften von Wasser und Eis, Vegaekspeditionens Vetenskapliga Iakttagelser, vol. 2, p. 247-323.

Pfann, W. G. (1958) Zone melting. New York: Wiley and Sons, 230p.

Sverdrup, H. U. (1929) The waters on the North-Siberian shelf, Scientific Results, Norwegian North Pole Expedition with the "Maud,"1918-1925, vol. 4, no. 2, p. $119-129$.

Tiller, W. A. (1963) Migration of a liquid zone through a solid: Part I, Journal of Applied Physics, vol. 34, no. 9, p. 2757-2762.

Wernick, J. H. (1956) Determination of diffusivities in liquid metals by means of temperature-gradient zone melting, Jourral of Chemical Physics, vol. 25, no. 1, p. 47-49.

(1957) Effects of crystal orientation, temperature, and molten zone thickness in temperature-gradient zone melting, Journal of Metals, vol. 8, p. 1169-1173.

Whitman, W. G. (1926) Elimination of salt from sea-water ice, American Journal of Science, vol. 11. no. 62, Fifth series, p. 126-132.

Wiese, W. (1930) Zur Kenntnis der Salze des Meereises, Ann. Hydrog. Maritim. Meteorol., vol. 58, p. 282-286.

Zubov, N. N. (1963) Arctic ice, Translation by U. S. Navy Electronics Laboratory, San Diego, California, $491 \mathrm{p}$.

Note:

After the contents of this report were published in the Journal of Geophysical Research (70,p. 5035-5041, 1965), an extensive discussion evolved about the determination of some of the parameters used in equation 5. Dr. R. G. Seidensticker (Westinghouse Electric Corporation) summarizes this discussion in a letter to the editor of the J. Geophys. Res. $(71,1966$, in press). He proposes to reduce the diffusion constant by approximately a factor 3. Also because of the different thermal. conductivities of ice and brine, the temperature gradient in the liquid pocket is higher by a factor 1.34 than the temperature gradient in the solid.

As a result of these two corrections a very good agreement between theoretical and experimental values was obtained. 
DOCUMENT CONTROL DATA - R\&D

(Security classification of title, body of abstract and indexing annotation must be entered when the overall report is classified) 1. ORIGINATIN G ACTIVITY (Comorate author)

U.S. Army Cold Regions Research and

Engineering Laboratory, Hanover, N.H. 2a. REPORT SECURITY CLASSIFICATION Unclassified

3. REPORT TITLE

MIGRATION OF LIQUID INCLUSIONS IN SINGLE ICE CRYSTALS

4. DESCRIPTIVE NOTES (TyPe of report and inclusive dates)

Research Report

5. AUTHOR(S) (Last name, first name, initial)

Hoekstra, P.; Osterkamp, T.E.; and Weeks; W.F.

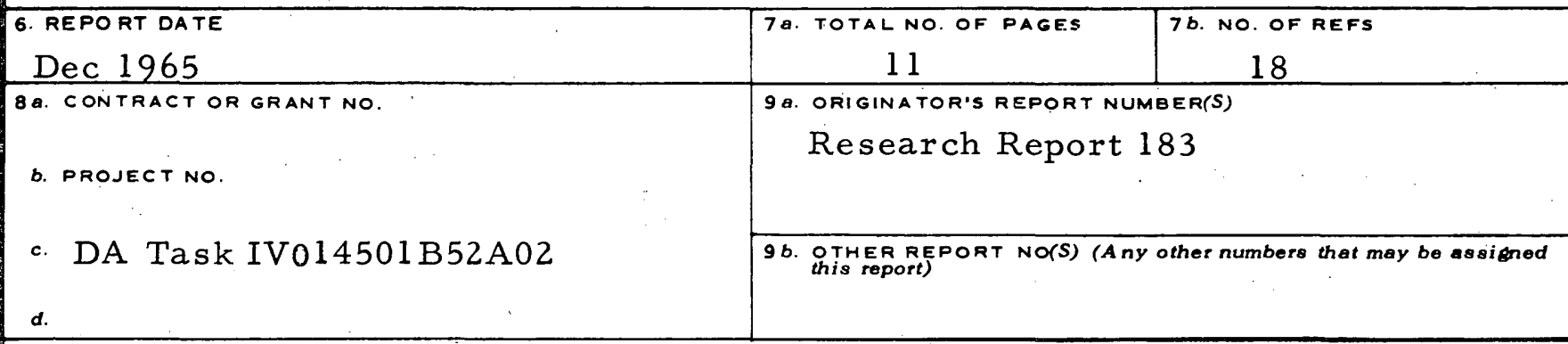

10. AVAILABILITY/LIMITATION NOTICES

Distribution of this document is unlimited

11. SUPPL EMENTARY NOTES

12. SPONSORING MILITARY ACTIVITY

U.S. Army Cold Regions Research and Engineering Laboratory

13. ABSTRACT

The migration of brine pockets of $\mathrm{KCl}$ and $\mathrm{NaCl}$ under the influence of a temperature gradient was investigated in single ice crystals. The observed migration velocities are compared with velocities calculated from asimple diffusion model using the data on electrolytic solutions available in the literature. Although the relative movements of $\mathrm{KCl}$ and $\mathrm{NaCl}$ pockets were consistent with the diffusion theory, the observed velocities were always less than the calculated. Neither the direction of the gravitational field nor the crystallographic orientation of the host crystal significantly influenced the rate of migration. It was also shown that the migration of solid KC1 particles occurs at temperatures below the eutectic point. Two mechanisms are proposed that would impede the mechanical differentiation of salts that crystallize at high temperatures relative to salts that remain in the brine of sea ice. These mechanisms explain recent field observations that the $\mathrm{SO}_{4} / \mathrm{Cl}$ ratio of sea ice does not increase with the age of the ice. 
Unclassified

Security Classification

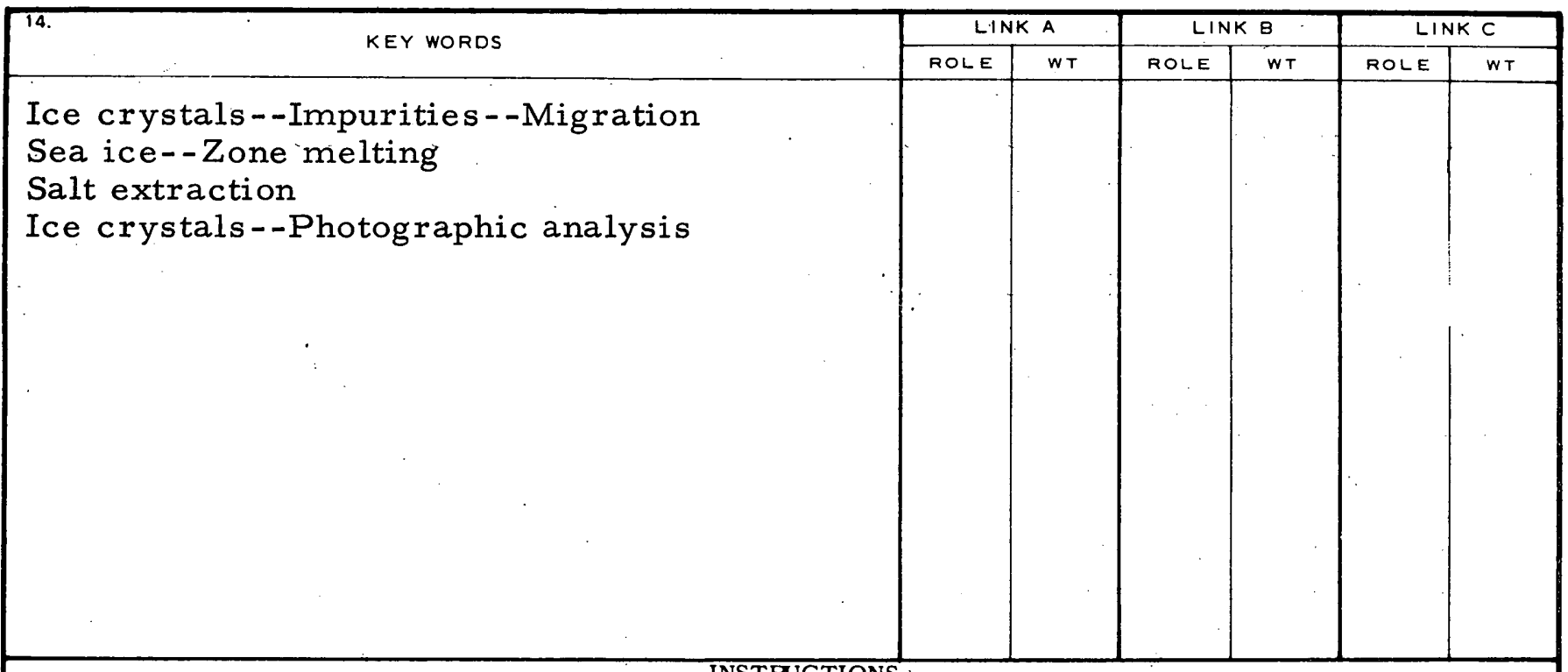

INSTRUCTIONS

1. ORIGINATING ACTIVITY: Enter the name and address of the contractor, subcontractor, grantee, Department of Defense activity or other organization (corporate author) issuing the report.

2a. REPORT SECURTY CLASSIFICATION: Enter the overall security classification of the report. Indicate whether "Restricted Data" is included. Marking is to be in accordance with appropriate security regulations.

2b. GROUP: Automatic downgrading is specified in DoD Directive 5200.10 and Armed Forces Industrial Manual. Enter the group number. Also, when applicable, show that optional markings have been us ed for Group 3 and Group 4 as authorized.

3. REPORT TITLE: Enter the complete report title in all capital letters. Titles in all cases should be unclassified. If a meaningful title cannot be selected without classification, show title classification in all capitals in parenthesis immediately following the title.

4. DESCRIPTIVE NOTES: If appropriate, enter the type of report, e.g., interim, progress, summary, annual, or final. Give the inclusive dates when a specific reporting period is covered.

5. AUTHOR(S): Enter the name(s) of author(s) as shown on or in the report. Enter last name, first name, middle initial. If military, show rank and branch of service. The name of the principal author is an absolute minimum requirement.

6. REPORT DATE Enter the date of the report as day, month, year; or month, year. If more than one date appears on the report, use date of publication.

7a. TOTAL NUMBER OF PAGES: The total page count should follow normal pagination procedures, $i_{\text {. }} e_{\text {, }}$ enter the number of pages containing information.

7b. NUMBER OF REFERENCES: Enter the total number of references cited in the report.

8a. CONTRACT OR GRANT NUMBER: If appropriate, enter the applicable number of the contract or grant under. which the report was written.

$8 b, 8 c, 8 d 8 d$. PROJECT NUMBER: Enter the appropriate military department identification, such as project number, subproject number, system numbers, task number, etc.

9a. ORIGINATOR'S REPORT NUMBER(S): Enter the of ficial report number by which the document will be identified and controlled by the originating activity. This number must be unique to this report.

9b. OTHER REPORT NUMBER(S): If the report has been assigned any other report numbers (either by the originator or by the sponsor), also enter this number(s).
10. AVAILABILITY/LIMITATION NOTICES: Enter any limitations on further dissemination of the report, other than those imposed by security classification, using standard statements such as:

(1) "Qualified requesters may obtain copies of this report from DDC",

(2) "Foreign announcement and dissemination of this report by DDC is not authorized."

(3) "U. S. Government agencies may obtain copies of this report directly from DDC. Other qualified DDC users shall request through

(4) "U. S. military agencies may obtain copies of this report directly from DDC. Other qualified users shall request through

(5) "All distribution of this report is controlled. Qualified DDC users shall request through "

If the report has been furnished to the Office of Technical Services, Department of Commerce, for sale to the public, indicate this fact and enter the price, if known.

11. SUPPLEMENTARY NOTES: Use for additional explanatory notes.

12. SPONSORING MILITARY ACTIVITY: Enter the name of the departmental project of fice or laboratory sponsoring (paying for) the research and development. Include address.

13. ABSTRACT: Enter an abstract giving a brief and factual summary of the document indicative of the report, even though it may also appear elsewhere in the body of the technical report. If additional space is required, a continuation sheet shall be attached.

It is highly desirable that the abstract of classified reports be unclassified. Each paragraph of the abstract shall end with an indication of the military security classification of the information in the paragraph, represented as (TS), (S), (C), or $(U)$.

There is no limitation on the length of the abstract. However, the suggested length is from 150 to 225 words.

14. KEY WORDS: Key words are technically meaningful terms or short phrases that characterize a report and may be used as index entries for cataloging the report. Key words must be selected so that no security classification is required. Idenfiers, such as equipment model designation, trade name, military project code name, geographic location, may be used as key words but will be followed by an indication of technical context. The assignment of links, rules, and weights is optional. 